\section{The End of Grand Strategy: US Maritime Operations in the Twenty-First Century}

Simon Reich and Peter Dombrowski

Cornell University Press, 2017

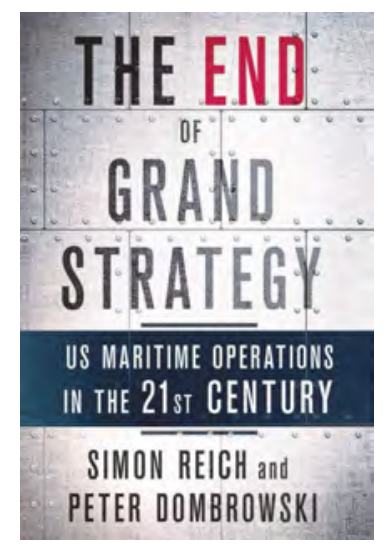

G rand strategy prescriptions figure strongly in American strategic debates. This book seeks to end those debates by proclaiming that the concept of grand strategy is obsolete. However, this book is more than that. It is actually two books in one, with more than half the pages devoted to examining in some detail a range of current US Navy operations. It is also an American-centric book. Indeed, it is made clear early on that only the US, as a 'truly great power' (p. 1), can have a grand strategy, or at least debate the possibility of having one.

Of the book's ten chapters, four are principally concerned with the concept of grand strategy, its shortcomings in theory and practice, and the theoretical construct that should replace it. The authors advocate adopting a typology of six strategies, which are derived from contemporary operations. The strategies, with somewhat simplified titles, are: Primacy; Leadership; Sponsorship (Formal and Informal); Restraint; and Isolationism. The remaining six chapters examine in an insightful and impressively detailed manner the specific US Navy operations these proposed strategies reflect. These practical case studies include operations in the Gulf, military diplomacy, anti-piracy missions, the Proliferation Security Initiative, emerging Arctic operations and the war on drugs. There is a strong focus here on peacetime naval missions.
Of particular interest is the discussion of the Leadership, Formal Sponsorship and Informal Sponsorship strategies. In common parlance, these are all engagement strategies where the US Navy works with and through others for the common good. Such strategies are inherently multilateral and involve operations where all parties cooperate and collaborate. This conceptualisation of engagement strategies, derived from contemporary real-world operations, is a useful counterfoil to the Trump administration's new strategic policy documents that perceive a world where all states ferociously compete and conflict looms large. The book highlights that the real world may be more complex and nuanced than these documents suggest.

The book's classification of engagement strategies into three types based on the mode of engagement is a most useful one. Often, multilateral and collaborative strategies are lumped together into one broad type. However, this approach does not allow for sufficient granularity to distinguish salient features. The book's engagement strategy classification schema, if adopted, will allow for better-structured thinking on multilateral military operations, particularly those other than war.

The book's biggest shortcoming is in the grand strategy chapters. The authors conflate the US National Security Strategy (NSS) with the concept of grand strategy. The NSS addresses certain matters of Congressional concern as required under the 1986 Goldwater-Nichols Act. The book convincingly challenges the NSS's present format mainly by stressing that one grand strategy cannot address all security concerns. However, the NSS is a particular example of a grand strategy, not the totality of grand strategy as an intellectual construct.

International relations thinker and practitioner John Ikenberry usefully divides grand strategies into two camps: the first is a milieu type, addressing the whole international system; the second is a positional type, addressing one specific state or a small group of states. Recent NSSs are examples of the relatively rare and demonstrably difficult to implement milieu type.

In sharp contrast, the highly regarded containment grand strategy of the Cold War era was a positional type. This grand strategy gradually grew to involve taking actions across the globe, however it was consistently focused solely on the bilateral relationship between the US and the USSR. For the US, the rest of the world comprised others who could help, hinder or distract from its grand strategy, but were considered unimportant in themselves, being seen instead in terms of the American-Soviet relationship.

In some respects, the book creates a strawman by equating the concept of grand strategy with the US NSS format and then deciding the format's failings prove grand strategy overall is an inadequate concept. Arguing a general point from a single narrow case study is rarely convincing but the authors in so trying make a pertinent point. As states are concerned with a variety of problems, they accordingly need and indeed use a variety of approaches to address them. This perspective is the rationale behind the six strategy types; one grand strategy - or rather one NSS - is insufficient, so there should be six strategies instead. These strategies should be carefully calibrated to be appropriate for their operating context.

The authors note that grand strategies should be reserved for stating 'what is desirable' (p. 6) with calibrated strategies undertaking 'what is feasible' (p. 12). Strategies, whether they are grand or not, try to bring about a particular objective a desirable future.

Conceptually, the book's proposed calibrated strategies seem to be determined more by context than the objectives they seek. This suggests that they are risk management approaches rather than strategies. The case study of naval operations in the war on drugs perhaps illustrates this. Such operations try to limit the flow of drugs into the US to a level where the damage caused is constrained to a tolerable level. There will always be criminals seeking large monetary returns, so stopping all drug importation does not seem to be a feasible objective. Given this, strategy is an inappropriate problemsolving technique when compared with a risk management approach that is shaped by and responds, as needed, to ongoing criminal events.

The book's core argument however, remains valid. A single, milieu-type, grand strategy as seen in the US NSS format \title{
Q1
Q2
}

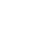


cannot address all the problems that trouble states. Having a variety of approaches is both useful and necessary.

The End of Grand Strategy: US Maritime Operations in the Twenty-First Century insightfully examines both the contemporary US NSS approach and current US Navy operations across the globe. While American-centric by intent, the book contains many concepts and ideas that smaller nations may find useful, especially in contemplating future multilateral naval operations, an area of growing importance. The book offers much for policymakers, military planners, academics and all those concerned with understanding the business of strategising.
Peter Layton is a Visiting Fellow at the Griffith Asia Institute at Griffith University. $\mathrm{His} \mathrm{PhD}$ is in grand strategy and he has taught on this at the US National Defense University. He is the author of the book Grand Strategy (2018).

DOI: XXXX 